\title{
Laser diagnostics for flame synthesis of nanostructured materials: instrumentation, metrology, and process control (Retraction Notice)
}

Xiaofei Liu

Xiaofei Liu, "Laser diagnostics for flame synthesis of nanostructured materials: instrumentation, metrology, and process control (Retraction Notice)," Proc. SPIE 7042, Instrumentation, Metrology, and Standards for Nanomanufacturing II, 70420G (9 September 2008); doi: 10.1117/12.795650

Event: NanoScience + Engineering, 2008, San Diego, California, United States 


\section{Laser diagnostics for flame synthesis of nanostructured materials: instrumentation, metrology, and process control (retraction notice)}

Proc. SPIE 7042, 70420G 2009); http://dx.doi.org/10.1117/12.795650

Online Publication Date: 9 September 2010

Retracted from Publication: 30 June 2010

Conference Date: Sunday 10 August 2008

Conference Location: San Diego, California, USA

Conference Title: Instrumentation, Metrology, and Standards for Nanomanufacturing II

Conference Chairs: Michael T. Postek, John A. Allgair

Xiaofei Liu

Rutgers Univ. (USA)

This paper (SPIE Paper 70420G) has been retracted by the author and was removed from the SPIE Digital Library on 20 October 2009. The original paper was published without the knowledge or consent of other collaborators, for which the author apologizes. As stated in the SPIE Guidelines for Professional Conduct and Publishing Ethics, "SPIE considers it the professional responsibility of all authors to ensure that the authorship of submitted papers properly reflects the contributions and consent of all authors." A serious violation of these Guidelines has occurred, necessitating that the paper be expunged from the conference proceedings. 